\title{
Research and Practice of Practical Teaching Management System In Institutions of Higher Learning
}

\author{
Ying ZHANG ${ }^{1, a}$ \\ ${ }^{1}$ Department of Teaching Affairs, Jilin Agricultural University, 130118, Changchun, China \\ aemail:jlauzy@126.com
}

Keywords: Pratical Teaching; Management System; Browser/Server

\begin{abstract}
This paper presents the development and design of the practical teaching management system based on $\mathrm{B} / \mathrm{S}$ mode and elaborate the construction process and implementation methods from the perspective of system requirement analysis, general system structure design, hardware and software environment for development and framework design.
\end{abstract}

\section{Introduction}

Practical teaching is the essential part of the teaching process in higher education and plays an incomparably important role in cultivation of comprehensive qualities and innovation ability of undergraduates. Practical teaching management is a key link of higher education in institutions of higher learning and also the basis and core of the overall management of the institutions of higher learning. In the face of various data and relevant reports, manual handling can hardly keep pace with the modern management. Along with fast development in computer technology and rapid popularization of the internet, practical teaching management in higher education are confronted with higher requirements. Therefore, it is of vital significance to reduce labor intensity of management staff, improve work quality and efficiency, facilitate inquiry of information by management staff and enhance utilization rate of information resources and management proficiency by construction of a students information system under the premise of popularity of the internet environment.

\section{Requirement Analysis of the System}

Practical teaching in colleges mainly embraces four links, namely experiment, practical training, internship, graduation project and graduation field work. Experiment, designed for specific course teaching, is a supplementary means to theory teaching in class and mainly includes campus experiment in laboratory in the campus. Practical training, designed for cultivation of a certain professional skill of students, mainly includes practical training inside and outside the campus divided by different projects. The practical is basically conducted in practical training base inside and outside the campus. Internship, mainly designed for cultivation of vocational capabilities of students, covers short-term teaching internship and in-post internship and mainly refers to internship outside the campus in practical training base outside the campus and cooperative enterprises. Graduation project and field work, belongs to a short-term practice project before graduation that shall be completed under guidance of the teacher. In this case, students are divided into several groups under the supervision of academic adviser.

Division of three-level management responsibilities in the management system is as follows:

First-level management: department of practice under the office of teaching affairs is responsible for establishing the guiding principles for macro management of the practical teaching of the school, coordinating the resources and information, formulating supportive management documents corresponding to the the practical teaching system and approval, dissemination of the practice projects and teachers' workload statistics .

Second-level management: the department of instruction, responsible for meso-management

of practical teaching for all majors in the school which the department belongs to, approval, reporting and management of the practical project applied by the teaching and research office of the 
department and teachers in the department.

Third-level management: the teaching and research section for a certain major, is responsible for specific implementation of the micro operation layer of the major and assisting the teachers in submission of the practice project.

Teachers' workload statistics, in the process of practical teaching management, inquiry, statistics of the teachers' workload shall be done in accordance with situation of teacher's guidance in the practical teaching and finally a report shall be submitted.

Management of training base inside and outside the campus: management of the training base inside the campus is mainly conducted respectively for each project with access to inquiry and statistics of the information concerning the training base. While, management of the training base outside the campus is mainly conducted respectively for each enterprise with access to inquiry and statistics of the information concerning such training base.

Laboratory assets management, mainly refers to management of the laboratory ( with experimental facilities) inside the campus included and access to inquiry and statistics of the conditions of the equipment and facilities in the laboratory. The system mainly aims at students, teachers, department and the practice center with the four kinds of practice projects, namely experiment, training, internship, graduation project \& field work. The business procedures include application for practice by the adviser, approval by the department, and then examination and further approval by the practice section before practice arrangements are publicized in the Internet. After the practice is over, the adviser shall input the students' practice results and students can make some suggestions on effects of the practical teaching.

The system mainly involves in four types of personnel, including administrative staff in the office of teaching affairs, department administrators, advisers and students. The administrative staff in the office of teaching affairs mainly refer to the staff members engaging in approval of the practice project who are in charge of secondary approval of the practice project. While, department administrators, refer to the administrative staff who are responsible for practical teaching of the department and initial approval and reporting of the practice project to the office of teaching affairs . Advisers are mainly in charge of application of the practice project and input of students' practice results. Students, can inquire the practice arrangements, practice results of themselves and feed back suggestions on the practical teaching.

\section{General Structure Design}

In light of functional requirements of system application, the practical management system is provided with the design of ten subsystems and one data interface: system maintenance, students' status management, teaching program management, curriculum arrangement management, course selection management, practical teaching management, textbook management, practice management, examination management, WEB management, and teaching quality assessment. Generally speaking, the system is based on a combined model of $\mathrm{C} / \mathrm{S}$ and $\mathrm{B} / \mathrm{S}$ for operational management. The practical management system for institutions of higher learning is basically consisted of two parts: first, the C/S structure which is primarily on functional sections and offices and secondary departments and provided with teaching program management, system maintenance, students' status management, curriculum arrangement management, course selection management, practical teaching management, textbook management, practice management, examination management, and teaching quality assessment. As to the $\mathrm{B} / \mathrm{S}$ structure, it mainly covers four modules for students, teachers, department and visitors with other status. In the student module, functions of online course selection, information inquiry, reporting, teaching assessment and other functions are offered; in the teacher module, input of practical teaching, information inquiry and maintenance is available; and in the department module, functions of information inquiry, distribution and teaching facilities management are provided; and other visitors can enjoy information inquiry and others. 


\section{Hardware and Software Environment for System Development}

Hardware mainly includes server: the server is the core for application and operation of the system and plays a decisive role in smooth running of the whole system. Therefore, it is necessary to select a high-performance dedicated server. To ensure the security and stability of system, 3 data servers and web application severs dedicated to IBM are used in design and application of the system. Meanwhile, in order to ensure data security, dual- machine backup in real time provided with 2G memory, 73*4 hard disk and Xeon double CPU are used for the data servers. In consideration of the data flow, the application server is provided with the same configuration and the software on the server is as simple as possible together with a highly reliable system- windows server 2003

As to selection of software platform on the client, windows2000/XP is used as operating system and SQL SERVER 2000 is used as database management tool. In addition, the general office software off ice2003 and Visual Studio 2005 are adopted for the ease of data import and export and routine processing.

\section{System Framework Design}

In design of the practical teaching management system, the mode combined with $\mathrm{B} / \mathrm{S}$ mode and C/S mode is used in this paper, which enables the system administrator to realize remote control more conveniently and quickly, and provides the users a handy and simple interface. Thus, all the users can enjoy the complete set of services provided by the system whenever and wherever possible via web browsing. Seamless connection is built between the management system and all sorts of software, thereby, the user can get access to various teaching information resources under system management by utilizing any software platform compatible with Windows system. As to framework design of the practical teaching management system, the present popular four-layer framework is adopted in this paper for the following reasons: in the practical management system, the information is updated more quickly, and it is often seen that, the system requirement has already changed when the previous practical management system is almost done, only to cause great trouble for system expansion. Therefore, the four-layer framework is used for ease of expansion and maintenance in the later period. Addition, modification, deletion and retrieval of the database is realized via the interface between the logical layer and the data layer. In the logic layer, logical functions of the integral system are realized, such as searching for multimedia resources and logical resources. When it comes to the data layer, data provider objects constitute the foundation of ADO.Net, and build a general database access layer by realization of various kinds of interfaces in it.

\section{Implementation of Practical Teaching Management System}

In terms of implementation of the business layer, which mainly help the users in data transfer and business process. It responds to the user request submitted in the visual interface of the presentation layer and obtains the required data by the user from the database and transfers it back to the presentation layer. The business layer also provides data verification of the data submitted, which means only the data meeting specific requirements can be submitted to the database for storage. On this basis, the business layer is the logic bridge connecting the user layer and data layer and performs two functions of providing submission of data and bringing forward regulations. For the business layer, module division is conducted by different functions of each part. According to different functions, the system can be mainly divided into four modules, namely login module, entry module, query statistics module and modification \& deletion module. Among the four modules, the business layer almost realize all the functions with the development technology of ASP.Net and MVC. With regard to implementation of the login module, the user will enter into the login module when they use the system and can successfully log into the system only after they entering their user name and password. The login program firstly checks the user name and the 
password and other information the user entered for legality and matching, and if the information is matched, log-in request is permitted; in case of illegal user, the login program will automatically give a prompt that the user shall restart login. After successful login, the program will record the privilege value of the user and read corresponding privilege from the data base. The user privilege value is decided by the user name, which is stored in the database by the system administrator beforehand. The authority includes system administrator and general user, and the former have all the privileges and the latter is given certain privileges corresponding to the privilege value.

\section{Conclusion}

Smooth development, operation and implementation of the system is based on concepts concerning system engineering and software engineering with full consideration of all links and influencing factors throughout implementation of the practical teaching management system. Besides, optimization and integration of the various data related to the practical teaching management system is carried out with the use of modern advanced computer technology, component technology, database technology and modular technology etc. to realize data sharing to the best extent and promote scientific, network and information construction of the practical teaching management system.

\section{References}

[1] Li Yiman. The design and implementation of practice teaching management system based on Java platform[J]. Information Technology and Informatization, 2008, 30(4):130-133.

[2] Liang Peng. Development and design of practical teaching management system[J]. Natural Science Journal of Harbin Normal University， 2009， 28(4):25-28.

[3] Deng Jianwen. Design and implementation of practice teaching management system based on network platform [J]. Journal of Jingdezhen University， 2009， 22(2):23-26.

[4] Nie Ying. Exploration of practice teaching management in quality oriented education in Colleges and Universities [J]. Education Exploration, 2001, 40(10):60-63.

[5] Yun Wenqiang. Practice teaching management in Higher Vocational Colleges [J]. China Modern Educational Equipment, 2012, 33(15):30-33. 